\title{
The Soviet Military City Plan of Florence (1986)
}

\author{
Alexander J. Kent ${ }^{\mathrm{a},}$ \\ ${ }^{a}$ Canterbury Christ Church University,UK alexander.kent@canterbury.ac.uk
}

Keywords: Soviet maps, city plans, Florence, military maps

\section{Abstract:}

During the Cold War, the Soviet Union mapped over 2,000 towns and cities around the globe in complete secrecy. Some of these plans have come to light after they were discovered in an abandoned depot outside Riga and were made available for sale at the $16^{\text {th }}$ International Cartographic Conference in Cologne, Germany, in 1993. Over the last few years, Soviet mapping has received an increased level of scholarly attention as more examples have emerged. The city plans, in particular, have become a particularly focussed topic of cartographic research, with new studies revealing insights into the processes of their production and offering evaluations of their purpose. The recent availability of official Soviet map production manuals has enabled further advances to be made in understanding the symbology and scope of this significant cartographic endeavour.

This paper focuses on the city plan of Florence (Figure 1), which comprises two sheets at 1:10,000 and was produced by the General Staff of the Soviet Union in 1986. The plan is produced according to the standard specification and symbology, and includes contours at 5-metre intervals. As is usual for the city plan series, the names of local areas and streets are transcribed into Cyrillic and to allow phonetic pronunciation by Russian speakers. The plan identifies 57 important objects (classified according to their strategic function), which are described in a numbered list in the margin, along with a street index and spravka - a descriptive essay about the city and its environs.

As well as providing an overview of the plan's main features and illustrating how various areas of the city are mapped in detail, this paper explores some possible source material and evaluates the Soviet attempt to map the city. By setting the plan within the wider context of the Soviet mapping of Italy, the paper discusses its strategic importance and provides an assessment of its historical value.

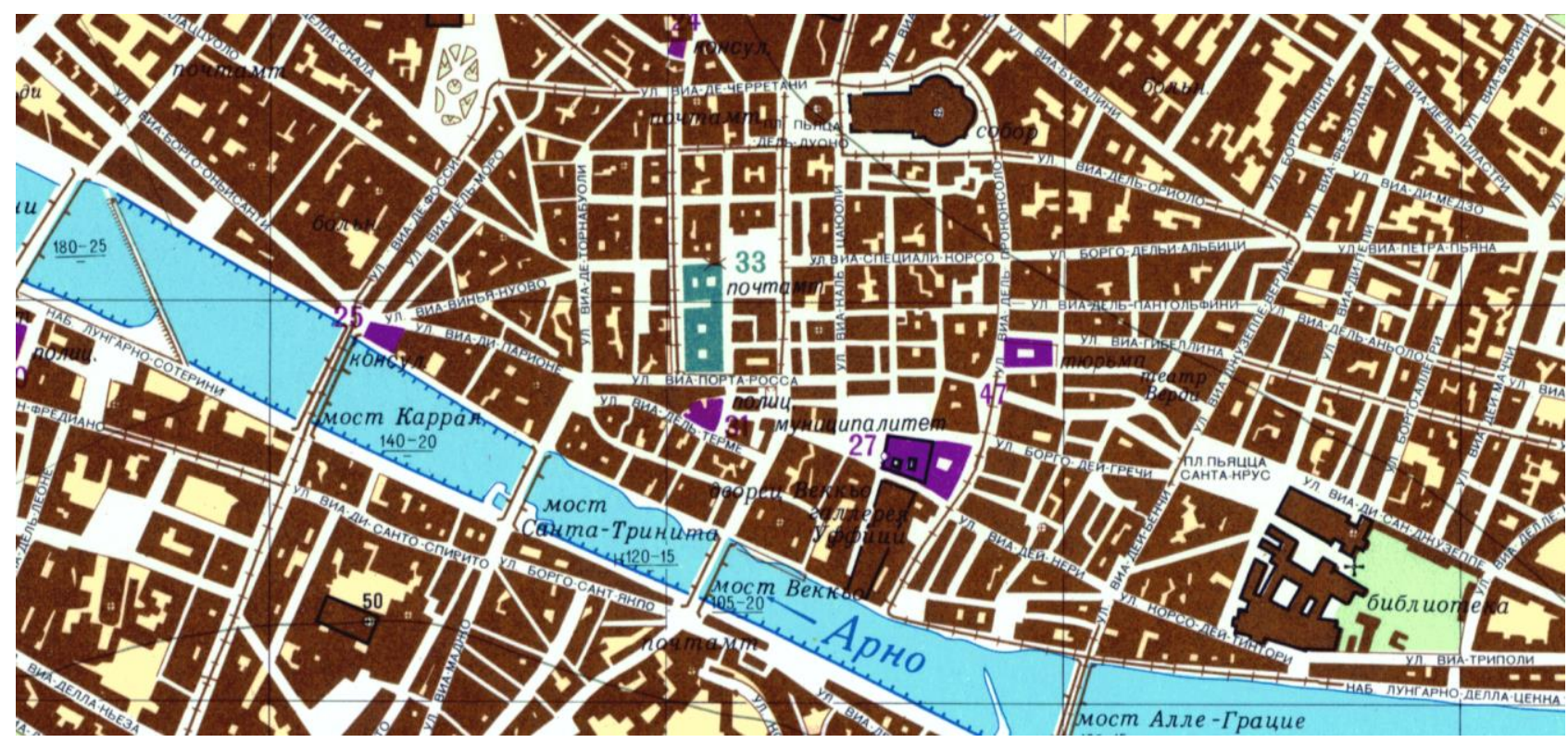

Figure 1. Detail from the Soviet Military 1:10,000 city plan of Florence (printed in 1986, private collection) 